\title{
2 A study on English communication skills at tertiary level
}

Citation: Lastname, F.; Lastname, $\mathrm{F}_{\dot{2} 4}$ Lastname, F. Title. Information 2021, 12, x. https://doi.org/10.3390/xxxxx 25

Publisher's Note: MDPI stays neu- 33 tral with regard to jurisdictiona 4 claims in published maps and institu35 tional affiliations.

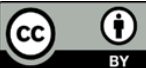
Submitted for possible open access 40 publication under the terms and 1 conditions of the Creative Common\$2 Attribution (CC BY) licens\$3 (https://creativecommons.org/licens 44 s/by/4.0/).

\author{
1 Ho Chi Minh City University off Food industry; huynhthu0810@gmail.com \\ * Correspondence: huynhthu0810@gmail.com; Tel.: +84 982898737
}

\begin{abstract}
Communication skills are one of the most important soft skills in the 21st century. There is a sad fact that even young Vietnamese, although learning English as an official subject at school, almost always show a lack of confidence when communicating with foreigners. Many high school graduates or even university students, when meeting foreigners, teachers or speaking in front of the class, still can not say anything more than simple questions such as greetings and introducing themselves. This study was conducted by the Ho Chi Minh City University of Food Industry (HUFI). With the participation of 120 students. Through the questionnaire. This study was for the purpose of indicating the errors that students make, as well as finding solutions that support their skills to learn and improve their ability to communicate. The results of this study showed the participation of 120 students. Only 50 out of 120 students received good reviews in the research, 45 students still lack skills and confidence when communicating and received an average rating. The rest of the 120 study participants were rated as weak, lacking a lot of communication skills. This condition needs to be interested in, as if not even when communicating with Vietnamese in English, you will lack confidence.
\end{abstract}

Keywords: Communication; communication skills; tertiary lever (or tertiary education);

\section{Introduction}

In general, communication might be described as the procedure of sending and receiving data from people giving the knowledge to the person receiving the knowledge via verbal and nonverbal strategies. The most common way to communicate is verbal, which may be a two-way process with responses to the received data. The sharing of thoughts, views, and knowledge for a shared goal is usually mentioned as communication. Apart from verbal communication, information can also be communicated by the utilization of symbols or signage. Language and textiles are is the 2 elements that have been parallel throughout history and are inseparable. Language itself is the culture of a country and culture can be expressed through language. Therefore, to learn the language better, you can take the time to learn about culture through cultural subjects as well as news channels. In this way, when understanding culture, language learning as well as using language are more efficient and appropriate. In addition, the job of loving and respecting a culture is also a springboard to promoting students to learn the language of that culture well. Communication is the process of passing information and understanding from one person to another. Therefore, all communication influences at least two people: the one who sends the message and the one who receives it. Consistent with this definition, elements of communication include the individual providing the knowledge, the infomation gained, and the receiver's feedback, with the replication of those processes leading to knowledge creation.

Additionally, for self-study, students should make the most of outside help, especially help and orientation from subject teachers. Instructors guide students to learn and 
develop English skills from simple to journal. At the same time, provide sufficient information to students so that students can understand the content, objectives and requirements of the training program.

Speaking is one of the important parts of English skills that should be mastered by students besides reading and listening. Speaking and most of all, communication skills play an important role in language proficiency. Many researchers have been conducted discussing the various problems facing Vietnamese learners of English. But few reports mention how to learn and how to apply communication skills in practice. Currently, there are still problems that need to be solved in learning English communication skills among students. Including lack of vocabulary, lack of speaking skills and lack of non-verbal communication-body language. This survey will show the current situation as well as some specific solutions to help students acquire proficient English communication skills.

\section{Literature review}

Since the 1970s, there have been many different conceptions of communication by different authors. Everyone looks at the problem from a different angle and gives different concepts:

(Kôlôminxki, 1981) described: "Communication is the interaction of objects and information between man and man".

(Tarone, 1997) has analyzied about communication is used by an individual to overcome the crisis which occurs when language structures are inadequate to convey the individual's thought". (Tarone, 1980) also provides a broad explanation of communication as a "mutual attempt of two interlocutors to agree on a meaning in situations where requisite meaning structures do not seem to be shared"

According to Nguyen Thac and Hoang Anh (1991), there are 4 signs of communication:

+ Communication is a phenomenon specific to humans, only humans have real communication.

+ Communication is a way of expressing relationships with one or more other people on the basis of economic and political relations in society.

+ Communication is carried out through the exchange of information and mutual understanding.

+ Communication is based on mutual understanding between people.

(Cleland, Foster, \& Moffat, 2005) They found that a positive communication environment provides opportunities for students to find ways to communicate, and thus, have better communication skills to be better prepared for the work market after completing their degree, university students should find ways to attach. When the individual receiving the message understands and practices the skills, communication improves. Communication is easier if the receiver of the information can understand and practice the skills. Further, communication are getting to be more meaningful if physical, spiritual and social factors are taken into account during the communication process. As a college student preparing to start their chosen profession, they ought to participate in any activities that improve communication skills in a broad and comprehensive manner to develop and improve communication skills. There are many kinds of communication skills, but generally it involves oral and written skills, there are essentially three sorts of communication, which are interpersonal communication, management communication (communication during a group), and public communication (speech making) has proposed by (Rahman., 2005).

Communication generally involves four elements, which are the speaker, the receiver, channel and feedback. Some researchers have defined communication as verbal communication, written language, non-verbal communication, listening and giving feedback. Concurrently, (Rodiah \& Idris, 2010) has said that communication as a non-verbal skill, giving feedback, presenting ideas verbally and in written form, doing presentations 
and negotiating to achieve a goal and getting agreement in our globalized world, university students have to master communication skills in several cultural contexts. As a response, universities need to provide plenty more ways to help students communicate more effectively to beat the stress of a globalized world. As a result, the aim of this study would be to look into the stage of communication skills of many students.

\section{Materials and Methods}

The questionnaire was designed using the available communication skills literature. The frameworks of communication skills (oral skills, reading skills, listening and social skills) during this paper were decided to use the communication definitions mentioned previously.

\subsection{Participants}

The research was carried out between March and May 2021, and included 120 students (aged from 18 to 24 years old), from Ho Chi Minh City University of Food Industry (HUFI). According to random selection, the distribution according to gender is uneven, as the sample includes 49 men $(40.83 \%)$, 70 women $(58.33 \%)$, and 1 gender $X(0.83 \%)$. They were asked to fill out a questionnaire. The data was collected and (was) analyzed.

\subsection{Assessments and Measures}

The questionnaire has eight questions, including four questions with a multiple choice format, and four questions with a one-to-five-number rating corresponding to the explanation of each number below:

$1=$ Worst/very unskilled.

$2=$ Not good/unskilled.

$3=$ Neutral/normal.

$4=$ Skilled.

$5=$ Very skilled.

\section{Results}

The questionnaire has been analyzed and linked according to each section having an impact on the other. Below are four headings, along with the charts to be analyzed.

\subsection{The correlation between study time and proficiency in essential English skills}

Through the questionnaire, it is easy to see how time (school year) affects students' proficiency in using English skills. Learning a foreign language is a complex, time-consuming process. That is, the development of the linguistic ability of learners is influenced by many influencing factors. The theory of second language acquisition covers many factors that are likely to affect language learning and development. These factors may be related to the teaching and learning process in the curriculum for a school year.

\subsection{Freshman and level of proficiency off essential English skills}




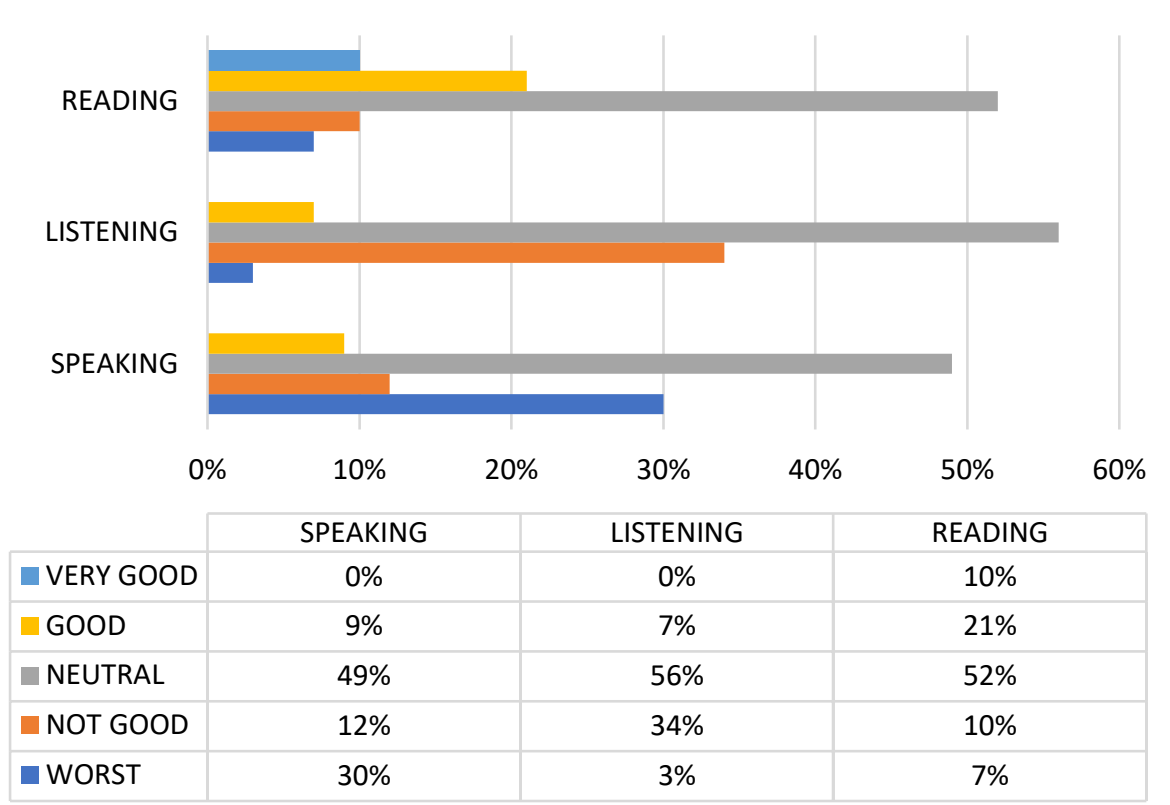

Table 1. Freshman and level of proficiency of essential English skills.

At HUFI, first year students will cultivate all four basic and essential skills in English: listening, speaking, reading, and writing. Most of the time studying is at school because students are not familiar with self-study at home, so most of them depend on lectures from books and knowledge passed from lecturers.

Speaking is one of the most critical and fundamental abilities that must be practiced to communicate orally. The factors affecting speaking skills are lack of subject, improper listening skills, lack of proper vocabulary, anxiety, and being overwhelmed by the fast and good grades of learners in the class. One common issue seen among freshman is that they think that they have nothing to say about a specific theme. In reality, they may be bored or feel that the subject is unrelated to anything they know. On the off chance that this is often the case, they will have no inspiration to talk other than the truth that they ought to be partaking in it effectively. This is because they are still dependent on topics limited to textbooks and have limited vocabulary. Attached was their anxiety about being asked to speak in English. Listening and reading skills are similar. Class time is limited and students are unfamiliar with having to study at home (except doing homework). All things have formed the habit of relying on, waiting for teaching from their class.

The above factors are also based on the questionnaire. It was concluded that freshman English-speaking skills were assessed as below average on a five-point scale. Listening skills are assessed on average, mainly because the lack of vocabulary also affects hearing ability. Reading skills are assessed to be simpler than speaking because there are already words in the text. Students will have no difficulty in looking up the meaning of words, so reading skills are assessed as fairly good.

\subsection{Sophomore and level of proficiency off essential English skills}




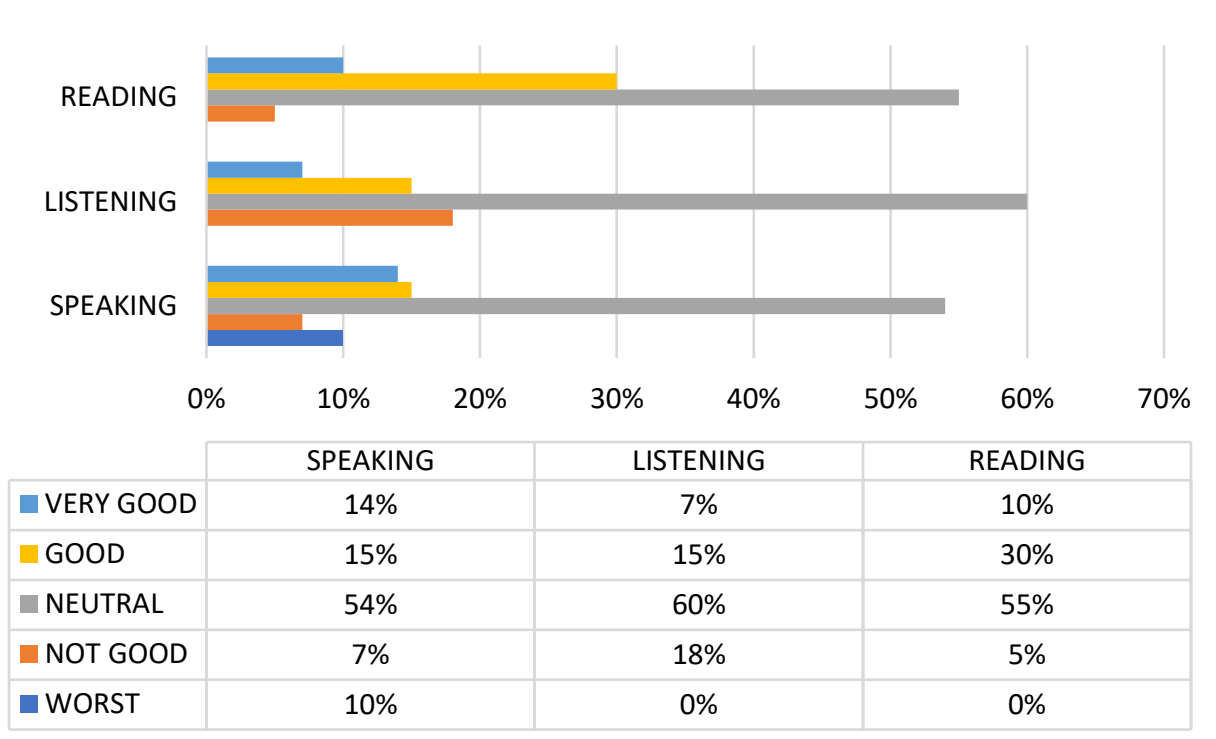

Table 2. Sophomore and level of proficiency of essential English skills

In the sophomore year, students are introduced to their majors. Sophomores are thoroughly instructed in theory as well as practical skills. From here on, the necessary skills will be gradually developed.

Sophomore students have gradually adapted to self-study, but few spend a great deal of time on it. Moreover, the ratings system has also been improved. Less "Worst" ratings, instead fairly good higher than the rating in Table 1. In Table 2, it was observed that assessment of speaking and listening skills improved from worse to better, as well as slight changes in the ratings of reading skills.

Students realized that studying at home was equally important to improving essential skills in English during the second year of study, after a first year of study with a surprise. This is the year during which the knowledge delivered by the faculty become extremely practical, no longer contingent upon the topics provided.

Likewise, the ability to listen and speak has greatly improved, since today's topics are diverse and the sophomores will not be worried about running out of things to talk about. Yet, the ability to speak relies on factors such as public speaking anxiety as well as poor performance in actual communication.

\subsection{Junior and level of proficiency off essential English skills}

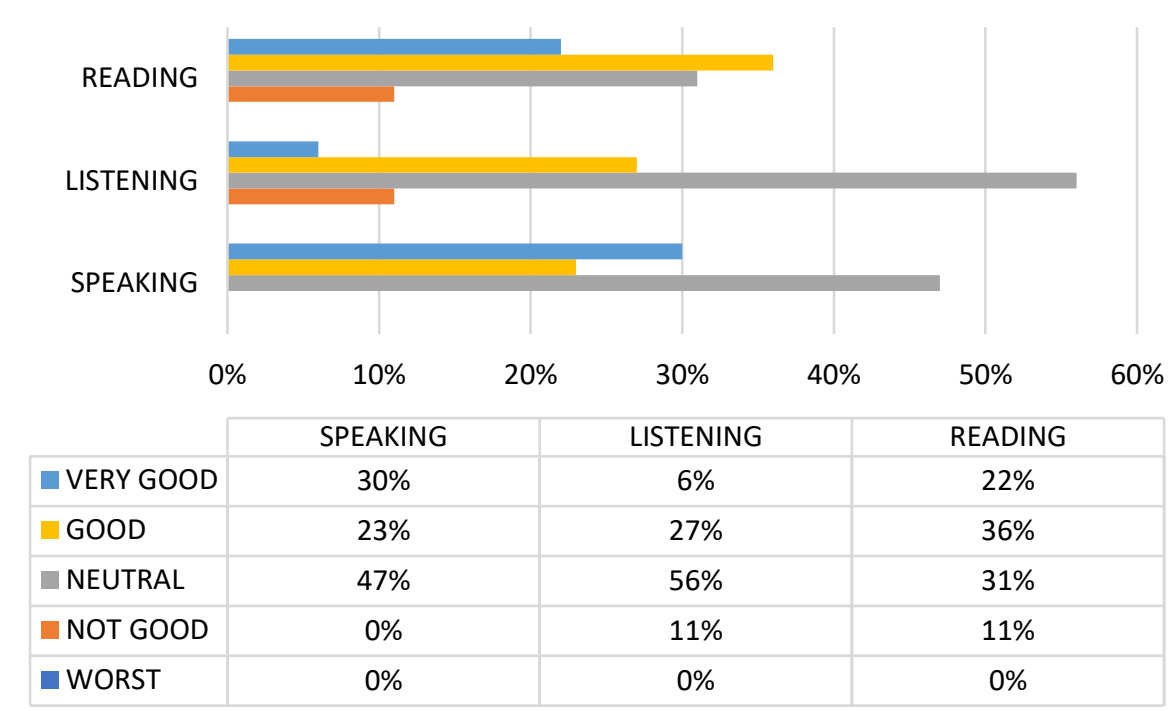

Table 3. Junior and level of proficiency of essential English skills 
The third year of education saw juniors being exposed to English in different fields, such as hotels, tourism, accounting, finance, and banking. Learning English through a variety of careers greatly improved vocabulary and sentence building skills. Besides learning English by profession. A translation and interpretation subject is also taught to juniors, which is crucial to improving their English language skills. During that period, listening and speaking skills were assessed as good, while reading skills were examined as fair.

\subsection{Senior and level of proficiency off essential English skills}

\begin{tabular}{|l|l|l|l|l|}
\hline READING & & & \\
\hline
\end{tabular}

Table 4. Senior and level of proficiency of essential English skills

All seniors completed all academic requirements at the school over the past four years in order to meet the English proficiency requirements. As seen in Table 4, English proficiency is ranked from good to excellent in the listening, speaking, and reading domains. Speaking level is dependent on the school year. Students' skills improve more quickly the longer they study.

\subsection{Genders affect communicating in English}

A total of 120 individuals took part in the survey, including 49 men (40.83\%), 70 women $(58.33 \%)$, and one gender $\mathrm{X}(0.83 \%)$. These results reveal that English learning is unequally distributed between men and women. In terms of gender and language, there are three main differences: First, language differences between men and women occur due to differences in human structure, including the position of language-containing regions in the brain, as well as differences in sound structure. A second difference is the language used by men and women, or, more specifically, the ways in which women speak. Languages have different words meant for different genders and some words that could not be used for another. Third, gender-based language differences can be seen in the dialects each gender speaks. The distinction is in the way the words are used; each gender uses words different from one another to describe the same issue. It's no secret that every gender receives or learns language differently. Learning styles differ among men and women, particularly when learning a second language (English). It has been observed that males possess a more powerful right hemisphere while females have a more balanced left hemisphere. Because of that, men can better visualize, understand space, or use logic, whereas women excel at vocabulary exercises, or in tasks related to music, humanities, etc.

There are significant differences between male and female learning styles. Males tend to be more motoric, tactile, and intuitive. Environments with a high level of dynamic information appeal to them. Additionally, they are less likely to follow the rules, but show 
better support for their partners than women. The chances of male students learning from listening are lower than those of female students. On the other hand, women tend to be hearing-oriented, and they abide by the rules of the class. Communication involves making decisions. This is one of the key components of communication. While many men show the opposite traits, women are more likely to demonstrate moderation. Therefore, this greatly hinders both genders' ability to communicate effectively in English when invited to have a conversation. Male students often speak briefly, sometimes make oppositional remarks, and often give emotional feedback. Despite the fact that female students are usually obedient when speaking in full sentences, they focus on the speaker and offer appropriate feedback.

Researchers have found that native speakers believe women communicate with tag questions, including polite words such as "please" or "thank you", as well as emphasizing words such as "very", "really," and so on. As opposed to women, men use short words like: "thanks" instead of "thank you", and "It is..." instead of "It is very...".

By analyzing this study, it is possible to conclude that gender really does exist in language communication. In terms of communication, a person's ability to communicate has two dimensions, the first is the gender-based influence on style and method, and the second is how gender is expressed through communication.

\subsection{Vocabulary size in communication.}

\section{Using dictionary when communicating with English to foreigners}

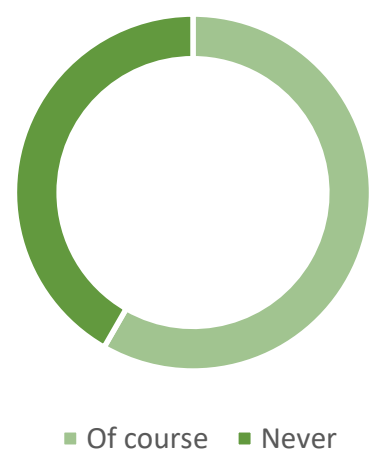

The density of HUFI students using dictionaries in English communication is very high. A total of 70 candidates (54.30\%) out of 120 participants stated that they all needed to use a dictionary while speaking. They also admitted that they were unaware of the context in which the word was used in terms of communication, and that they did not know how to reply in English. The students mentioned using dictionaries to look up words, match sentences, and then converse with native speakers. These results indicate a lack of vocabulary among students. Unlike the mother tongue, the second language (here English) requires constant updating in terms of the usage and meaning of words.

Indirectly, vocabulary impacts a student's communication skills; a limited vocabulary makes communication more challenging for students. The English language has a number of different meanings, which is why words are used in an inflexible way when learning them. Over time, this negatively affects their communication skills, leading to decreased confidence in communication. It is common for students to learn a word's main meaning, but, in reality, each English word has a plethora of different meanings. Furthermore, students often don't pay much attention to learning the correct pronunciation of 
words, leading to students making lisper pronunciations that alter the meaning of the sentence. Consequently, the survey found that students generally have an average vocabulary size. It is therefore imperative to practice and to increase the amount of vocabulary every day to avoid being surprised when communicating.

4.8 Body language enhances English communication

\section{Using body language \\ when communicating}

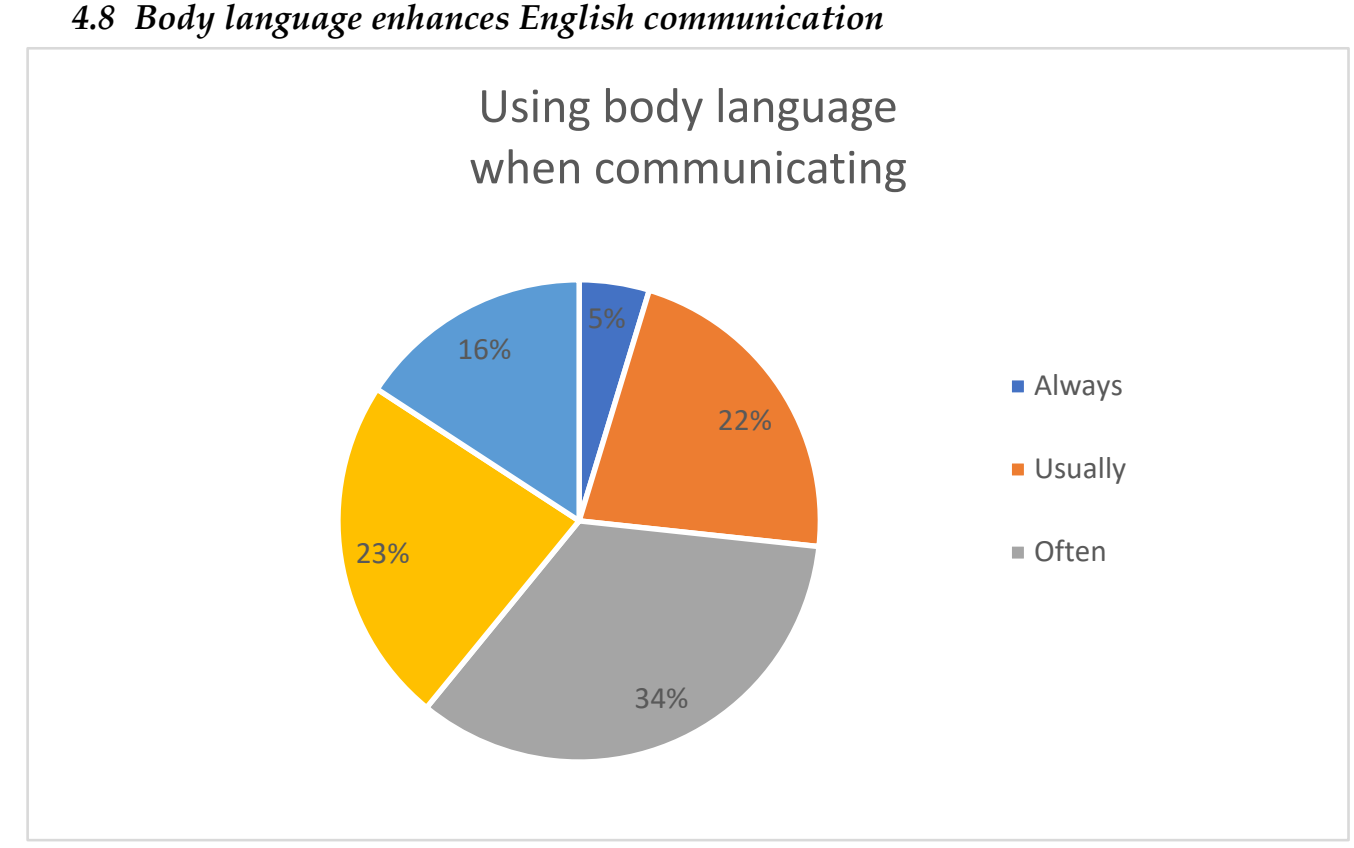

Body language is rarely used in communication, as shown by the chart. When students were asked how they usually express themselves, they said that they stand upright, cross their arms, or hold their hands together. These people do not even make simple gestures like nodding in support of the speaker or smiling upon receiving a compliment; rather, they simply say "thank you" to the speaker.

Language is used to express someone's thoughts, intentions, or conditions, and can also be used to conceal or distract them. A language associated with consciousness should be controlled by consciousness. Furthermore, there is an unattached kind of language, called body language, that has little or no connection with the conscious mind. In the communication process, gestures, facial expressions, and limb movements are utilized by this language.

An individual's speech is composed of three elements: language, non-verbal cues, and tone. In which language accounts for only $7 \%$ of the impact on the listener, $38 \%$ is due to tone, and $55 \%$ is due to nonverbal communication of body language. University of California, Los Angeles psychology professor Albert Mehrabian is responsible for establishing this rule. This conclusion was reaffirmed by Dr. Ray Birdwhistell - Professor of Psychiatry at the University of Pennsylvania, that listeners receive $7 \%$ of words and content; $38 \%$ of the content words (voice: press, stop, high, low, loud, small...) and 55\% are not related to words, such as posture, costumes, movements, swing, facial expressions... of the speaker.

\section{Discussion}

In the fourth part of the paper (Results), the scientists raise a number of issues. Here, the survey suggests possible solutions. In particular, the following recommendations focus on improving communication skills in English and learning English with greater precision among university students in general, as well as HUFI students. There is no doubt that learning and using English as fluently as a native speaker can be very challenging. Practicing a second language daily and continuously helps promote knowledge that can 
be readily applied in practice. All the solutions listed below are not the fastest solutions for students, but they can be applied immediately, and the effects will improve gradually.

\subsection{Self-study}

It is essential to constantly practice and improve your English, classroom lectures are time-limited, and teachers can not solely focus on teaching an individual and ignore others. Self-study is the best method. You will not be able to learn anything by waiting for class and may not even comprehend what the instructor has said, so students should decide what time makes the most sense to study.

Do students work or study more efficiently in the mornings or afternoons? Choose for the individual a period of time during which the individual's brain is most focused on language learning. The English language can be studied through online courses as well as apps in every individual's spare time. Students can study wherever they want, at any time.

\subsection{Improve vocabulary size}

Language is based on vocabulary. It is the "backbone" of communication in English. Due to its high vocabulary size, it helps individuals acquire other skills. When grammar is absent, not much information can be communicated. Vocabulary is crucial, but without it, you can't communicate anything. There can be no doubt that it is the most accurate conclusion about the importance of vocabulary. The following are some tips that can help students overcome difficulties with vocabulary learning:

+ Make sure you learn slowly according to your level and develop gradually. Avoid studying at an intricate level. If an individual does not know their level, they can not choose the right study program. Thus, students will make a list of appropriate vocabulary to focus on according to their level. There is no need to learn all the words since you will have difficulty remembering them. In the learning process, it is important to remember not to force yourself to memorize or rote study. In order to become familiar with English words, it is necessary to practice them. It is a very effective way to learn English vocabulary that you need to remember.

+ Learn words through books, movies, and music, which also happens to be the most frequently heard advice. Start by presenting information on topics that are familiar, rather than overwhelming, specialized information. It is not necessary for individuals to look up every new word in a dictionary. Continuously searching will interrupt thinking, making the ability to receive information more limited. To determine what the idea is, you should highlight unknown words in context, or based on related words in a sentence.

\subsection{Improve vocabulary size}

A third way to reinforce the word is by applying it immediately after learning it; repeating it repeatedly and doing some extra activities to reinforce the word. Almost anything that is repeated in a repetitive manner requires more time for memorization. Regular testing will do more than help students gauge their level. Nothing is harmful about this, it is only beneficial. It is essential that students have access to high-quality vocabulary learning resources. Students can find English vocabulary learning websites that develop online vocabulary for mainstream units, as well as application software that is developed by reputable units. E.g.:

1. https://www.vocabulary.com

2. https://quizlet.com

3. https://dictionary.cambridge.org

4. https://www.oxfordlearnersdictionaries.com

\subsection{Speaking slowly}

The fourth item is the speed of speech, also the most important issue students need to be aware of. It's common for students to say that they surf the internet often, which is 
not good. Considering the personal starting point is that of a language learner, not a native speaker, the pronunciation and speaking speed will be different from that of a native speaker. Even though a student can answer without thinking, students should slow down their speech. Students may worry that the person they are speaking to is not patient enough, so they will try to speak quickly, but this is not a good idea. The reason is that people often want an honest answer, which is also a sign that you value their opinion. But silence is also disrespectful, as it can give the individual time to think by inserting words with different contexts such as "Well", "Basically" and "Honestly", or "Oh, yeah", "You know", and "I mean"... You need to insert a lot of words when searching for the right answer, so to do this, you need to learn more vocabulary.

\section{Conclusions}

The purpose of this study is to investigate how university students' English communication skills have improved over their years at HUFI. The research paper consists of eight survey questions that are selected and evaluated by the students themselves. The survey was analyzed and the above results were given (in the Results and Discuss section). The survey is analyzed into four parts as follows: First, the correlation between study time and proficiency in essential English skills. This section is based on the academic year along with the students' evaluation of their own work. Second, genders affect how we communicate in English. Based on gender, the analysis of factors related to the communication ability of the two different genders is given. Third, vocabulary size in communication. The analysis is based on the amount of vocabulary that students have, thereby analyzing students' ability to use a dictionary when practicing communication with native speakers. The last part - body language enhances English communication. Known as a communication aid, this section will analyze the gestures and actions of students when communicating face-to-face. Along with the analysis are the recommendations that have been given. And the important part is have realistic expectations is important for the learner. Set goals that are consistent with your abilities. Do not rush, do not be impatient, and be patient. Moreover, it takes at least two years for native speakers to speak their first words as children are only able to listen before they speak. This means you can not master a language in a matter of weeks or months. Additionally, students should not put pressure on teachers to completely improve their English. It's up to you to learn. The teacher is just a guide, giving methods to learn. Whether you go far or not depends on your feet, your thoughts. Since there are 40 students in a class, the teacher shares the same amount of knowledge with all of them. Practicing both speaking and listening skills every day is key to improving communication skills, and in order to fluently communicate in English, students need to practice every day. The role of listening is to receive information from the speaker, and the role of speaking is to give back information. The ability to communicate in English at any time is gained by using English often, not just in the classroom. Never be afraid to make errors when communicating in English because native speakers sometimes make errors in their communication and also need to correct them. Students should not be too dependent on the dictionary to guess the meanings of words and sentences by referring to the content of the reading text, listening text and communication situations, because this fosters bad habits. A dictionary isn't always carried or used. Students will notice significant improvements in results by using these methods for about 2-3 months. It is hoped that if this research topic is undertaken again, based on the efforts of the students, it will produce a better result than the current one.

\section{Patents}

Funding: This research received no external funding

Conflicts of Interest: The authors declare no conflict of interest. 


\section{Appendix}

Survey questions investigating for English communicating skills.

1. Your gender:

Male

Female

$X$

2. Year of learning:

Freshman

Sophomore

Junior

Senior

3. Level of proficiency in speaking skills in English ?

$1=$ Worst $/$ very unskilled

$2=$ Not good $/$ unskilled

$3=$ Neutral $/$ normal

$4=$ Skilled

$5=$ Very skilled

4. Level of proficiency in listening skills in English ?

$1=$ Worst $/$ very unskilled

$2=$ Not good $/$ unskilled

$3=$ Neutral $/$ normal

$4=$ Skilled

$5=$ Very skilled

5. Level of proficiency in reading skills in English ?

$1=$ Worst $/$ very unskilled

$2=$ Not good $/$ unskilled

$3=$ Neutral $/$ normal.

$4=$ Skilled

$5=$ Very skilled

6. Level of availability when communicating with foreigners ?

Unwilling

Neutral

Willing

7. Using dictionary when communicating with foreigners ?

Yes

No

8. Level of using body language when communicating with foreigners ?

$1=$ Never

$2=$ Sometimes

$3=$ Often

$4=$ Usually

$5=$ Always

\section{References}

1. Cleland, Foster, \& Moffat. (2005). Undergraduate students' attitudes to communication skills learning differ depending on year of study and gender.

2. Chiavenato, \& Idalberto. (2006). Introduction to the General Theory of Administration. Spain: McGraw-Hill Interamericana.

3. Hernández, A., \& Garay, O. (2005). Communication in the sport context. Spain: Wanceulen Editorial Deportiva, S.L. 
4. Kôlôminxki. (1981). Nhĩung cơ sở của tâm lí học sư phạm. Nhà xuất bản Giáo dục.

5. Martínez, \& Nosnik. (1998). Practical Organizational Communication. Mexico.: Editorial Trillas.

6. Rahman., M. H. (2005). Malaysia: Siti Rahaya Ariffin, Shahrir Abdullah \& Abd.

7. Rodiah, \& Idris. (2010). Pemeriksaan Ciri-ciri Psikometrik dan Pembentukan Penanda Aras Pentadbiran Kemahiran Genarik. Malaysia.

8. Tarone. (1980). Communication strategies. Washington DC.

9. Tarone. (1997). Conscious communication strategies in interlanguage. Washington DC.

10. Thạc, N., \& Anh, H. (1991). Vài thực nghiệm về KNGT sue phạm của sinh viên vốn có nhu cầu giao tiếp khác nhau. Việt Nam: Tạp chí nghiên cứu Giáo dục.

11. Wikipedia contributors. (2021, May 6). https://en.wikipedia.org/wiki/Tertiary_education. Retrieved from en.wikipedia.org: https://en.wikipedia.org/wiki/Tertiary_education 